\title{
Physicochemical characterization and solubility enhancement studies of allopurinol solid dispersions
}

\author{
Jagdale Swati Changdeo, Musale Vinod, Kuchekar Bhanudas Shankar, \\ Chabukswar Anuruddha Rajaram
}

\author{
Maharashtra Academy of Engineering and Educational Research, Maharashtra Institute of Pharmacy, Maharashtra, India
}

\begin{abstract}
Allopurinol is a commonly used drug in the treatment of chronic gout or hyperuricaemia associated with treatment of diuretic conditions. One of the major problems with the drug is that it is practically insoluble in water, which results in poor bioavailability after oral administration. In the present study, solid dispersions of allopurinol were prepared by solvent evaporation, kneading method, co-precipitation method, co-grinding method and closed melting methods to increase its water solubility. Hydrophilic carriers such as polyvinylpyrrolidone, polyethylene glycol 6000 were used in the ratio of 1:1, 1:2 and 1:4 (drug to carrier ratio). The aqueous solubility of allopurinol was favored by the presence of both polymers. These new formulations were characterized in the liquid state by phase solubility studies and in the solid state by differential scanning calorimetry, powder X-ray diffraction, UV and Fourier Transform Infrared spectroscopy. Solid state characterizations indicated that allopurinol was present as an amorphous material and entrapped in polymer matrix. In contrast to the very slow dissolution rate of pure allopurinol, the dispersion of the drug in the polymers considerably enhanced the dissolution rate. Solid dispersion prepared with polyvinylpyrrolidone showed highest improvement in wettability and dissolution rate of allopurinol. Mathematical modeling of in vitro dissolution data indicated the best fitting with Korsemeyer-Peppas model and the drug release kinetics primarily as Non-Fickian diffusion. Therefore, the present study showed that polyvinylpyrrolidone and polyethylene glycol 6000 have a significant solubilizing effect on allopurinol.
\end{abstract}

Uniterms: Allopurinol. Polyethylene glycol 6000. Solid dispersions. Closed melting method. Dissolution enhancement.

\begin{abstract}
Alopurinol é fármaco comumente utilizado no tratamento de gota crônica ou hiperuricemia associada com o tratamento em condições diuréticas. Um dos maiores problemas com o fármaco é que este é praticamente insolúvel em água, o que resulta em baixa biodisponibilidade na administração oral. No presente estudo, dispersões sólidas de alopurinol foram preparadas pela evaporação do solvente, pelos métodos de amassamento, de coprecipitação, de comoagem e fusão fechada para aumentar sua solubilidade em água. Transportadores hidrofílicos, como polivinilpirrolidona, polietilenoglicol 6000 foram utilizados nas proporções de 1:1. 1:2 e 1:4 (fármaco: transportador). A solubilidade aquosa do alopurinol foi favorecida pela presença de ambos os polímeros. Estas novas formulações forma caracterizadas no estado líquido pelos estudos de solubilidade de fase e no estado sólido pela calorimetria diferencial de varredura, difração de Raio-X, espectroscopia de UV e de IV com transformada de Fourier. As caracterizações do estado sólido indicaram que o alopurinol estava presente como material amorfo e embebido em matriz polimérica. Ao contrário da velocidade de dissolução lenta do alopurinol puro, a dispersão do fármaco nos polímeros aumentou consideravelmente a taxa de dissolução. A dispersão sólida preparada com polivinilpirrolidona mostrou as maiores melhorias na molhabilidade e taxa de dissolução do alopurinol. A modelagem matemática dos dados da dissolução in vitro indicou o melhor ajuste ao modelo de Korsemeyer-Peppas e a cinética de liberação do fármaco primariamente como difusão não-Fickiana. Assim, o presente estudo mostrou que a polivinilpirrolidona e o polietilenoglicol 6000 têm efeito significativo na solubilização do alopurinol.
\end{abstract}

Unitermos: Alopurinol. Polietilenoglicol 6000. Dispersões sólidas. Método de fusão fechada. Aumento da dissolução.

\footnotetext{
*Correspondence: Dr. Swati C. Jagdale. Department of Pharmaceutics, MAEER's Maharashtra Institute of Pharmacy, S.No 124, MIT Campus, Kothrud, Pune - 411 038, Maharashtra, India. E-mail: jagdaleswati@rediffmail.com
} 


\section{INTRODUCTION}

Allopurinol (ALLO), chosen in the current study, is a poorly water-soluble drug known to demonstrate limited dissolution- or solubility-limited absorption (Ahuja et al., 2003). Based upon aqueous solubility and various dissolution parameters, several methods have been employed to improve the solubility of poorly water soluble drugs including increasing the particle surface area available for dissolution by milling (Habib et al., 1985) improving the wettability with surfactants or doped crystals, (Chow, 1995) decreasing crystallinity by preparing a solid dispersion (Flego, 1988), use of inclusion compounds such as cyclodextrin derivatives (Pitha, 1985), use of polymorphic forms or solvated compounds (Sekiguchi, 1973), and use of salt forms.

The enhancement of the bioavailability of poorly water-soluble drugs is one of the greatest challenges of drug development and several pharmaceutical technologies have been investigated to this end. Amongst them is the solid dispersion of one or more active ingredients in inert carriers at solid state prepared by fusion, solvent, or solvent-fusion methods (Damian et al., 2000). In solid dispersions, the particle size of the drugs was reduced, and the wettability and the dispersibility of the drugs were enhanced. Consequently, drug dissolution was improved markedly (Craig, 2002). Solid dispersion is a promising approach to improve the dissolution and bioavailability of hydrophobic drugs (Abdul-Fattah et al., 2002).

Hydrophilic polymers have been commonly used as carriers for preparing solid dispersions. Among them, polyvinylpyrrolidone (PVPk30) has been widely employed for its high aqueous solubility, high physiological tolerance, and low toxicity. Polyethylene glycols (PEGs) are semi crystalline polymers that have been used extensively in solid dispersion preparations for their wetting, solubilizing and surface active properties (Sethia et al., 2004).

In recent years, interest in incorporating a surfaceactive carrier into solid dispersion has increased greatly and a high improvement in drug dissolution was reported (Serajuddin, 1999; Pathak et al., 2008). This approach has been reported to enhance the solubility, dissolution and bioavailability of many poorly water soluble drugs using various techniques including melting agglomeration and melting. The present study was planned to improve the aqueous solubility and dissolution rate of ALLO by preparing the solid dispersion with polyethylene glycol 6000 (PEG 6000) and PVPk30 employing various methods such as solvent evaporation (SE), co-precipitation (CP), co-grinding (CG), kneading (KN) and the closed melting method (CM). The study further aimed to characterize the interaction of ALLO with PEG 6000 and PVP K30 in the solid state by Fourier Transform Infrared Spectroscopy (FTIR), Differential Scanning Calorimetry (DSC), and Powder X-Ray Diffraction (PXRD) to check the dissolution behavior of solid dispersions.

\section{MATERIAL AND METHODS}

\section{Material}

Allopurinol (ALLO) was kindly supplied by Nicolas Piramal, (Pitampur, India) and PVPk30 was obtained from Oxford Laboratory (Mumbai, India). PEG 6000 was purchased from Analab Fine Chemicals (Mumbai, India). All other chemicals and solvents were of analytical reagent grade. Freshly prepared distilled water was used throughout the study.

\section{Methods}

\section{Phase solubility studies}

Solubility measurements were performed in triplicate using the method reported by Higuchi and Connors (Higuchi et al., 1965). An excess amount of ALLO was added to the aqueous solutions of each carrier containing increasing concentrations of the individual carrier (i.e., 0 , $1,5$, and $10 \% \mathrm{w} / \mathrm{v})$. The flasks were then maintained at $25^{\circ} \mathrm{C}$ for 7 days with continuous stirring by a magnetic stirrer. The saturated solution was sonicated for $20 \mathrm{~min}$. and then centrifuged; the supernatant were filtered through a whatman filter paper no. 1 . The filtrate was suitably diluted and analyzed spectrophotometrically at $\lambda \max 250 \mathrm{~nm}$ on a Varian carry 100, UV-Vis Spectrophotometer, Australia (Ahuja et al., 2007).

\section{Preparation of physical mixture and solid dispersions}

- Physical mixtures (PM)

For the sake of comparison, physical mixtures (PM) of ALLO were prepared by mixing accurately weighed amounts of ALLO with carriers (ratio of drug: carrier was $1: 1,1: 2$ and $1: 4)$ in a mortar by simple trituration.

\section{- Solvent evaporation method (SE)}

SDs were prepared by dissolving accurately weighed amounts of ALLO and PEG 6000 in ethanol. After complete dissolution of ALLO and PEG 6000 in ethanol the solution was sonicated for 20 minutes, and then solvent was evaporated under reduced pressure at room temperature in a dessicator. Subsequently, the solid mass was ground through sieve no. 40 . The sieved 
ground powders were kept in an oven for $48 \mathrm{hrs}$ at $60{ }^{\circ} \mathrm{C}$ (George et al., 2006).

- Co-grinding method (CG)

ALLO was triturated with the minimum quantity of ethanol in a glass mortar until dissolved. PEG 6000 was then added and the suspension triturated rapidly at room temperature until the solvent evaporated. The resulting powder was passed through sieve no 40 (Nokhodchi et al., 2007).

- Kneading method (KN)

A mixture of ALLO and PEG 6000 was wetted with water and kneaded thoroughly for 30 minutes in a glass mortar. The paste formed was dried under vacuum for 24 hrs. Dried powder was passed through sieve no. 40 and stored in a dessicator until further evaluation (Modi et al., 2006).

- Co-precipitation method (CP)

SDs were prepared by dissolving accurately weighed amounts of PEG 6000 in water and drug in ethanol. After complete dissolution, the aqueous solution of the carrier was then poured into the ethanolic solution of the drug. The solvents were then heated and evaporated under reduced pressure at room temperature in a dessicator. Subsequently, the solid dispersions were passed through sieve no. 40 and kept in an oven for $48 \mathrm{hrs}$. at $60^{\circ} \mathrm{C}$ (Dixit et al., 2007).

\section{- Closed Melting method (CM)}

One gram of physical mixture of PEG 6000 was weighed into glass ampoules $(20 \mathrm{ml})$ which were sealed and then heated for 30 minutes in a water bath to prepare the solid dispersions. After slow cooling, the ampoules caps were opened and the solid dispersions collected. All dispersions were pulverized with a pestle and mortar, passed through sieve no. 40 and dried in an oven for at least 48 hrs. at $60^{\circ} \mathrm{C}$ (Hasegawa et al., 2005).

Similar procedures were carried out to prepare solid dispersions containing PVP K30. Due to the hygroscopic nature of PVP K30 sticky lumps are formed by CP and $\mathrm{CM}$ methods. Therefore, these solid dispersions are not applicable for evaluation and characterization studies.

\section{Characterization of solid dispersions}

All the formulations were evaluated by phase solubility studies and in-vitro dissolution studies. Solid dispersions are also characterized by UV, FTIR, DSC and PXRD analysis.
- Fourier Transform Infrared spectroscopy (FTIR) studies FTIR spectra of pure ALLO, PVP, PEG, solid dispersions and physical mixture were recorded on a 640 IR, Varian device, Australia, using the $\mathrm{KBr}$ pellet method involving trituration of $10 \mathrm{mg}$ of solid dispersions with $10-20 \mathrm{mg}$ of dry $\mathrm{KBr}$ powder and filling of pellets with this for scanning at 4000 to $400 \mathrm{~cm}^{-1}$.

\section{- UV-Visible Spectroscopy}

UV-Visible Spectroscopy was performed by weighing solid dispersions accurately and dissolving in dilute $\mathrm{NaOH}$ solution, sufficiently diluting with distilled water to produce a final concentration of $10 \mu \mathrm{g} / \mathrm{ml}$ (Londhe et al., 1999). These solutions were scanned spectrophotometrically in the UV region at $260 \mathrm{~nm}$ on a Varian carry 100, UV-vis Spectrophotometer, Australia.

- Differential Scanning calorimetry (DSC) studies

A differential scanning calorimeter (DSC-823e, Mettler Toledo, Switzerland) was used to obtain the DSC curves of ALLO, its physical mixtures and solid dispersions. About $10 \mathrm{mg}$ of sample was weighed in a standard open aluminum pan, and scanned from $20-450{ }^{\circ} \mathrm{C}$ at a heating rate of $10^{\circ} \mathrm{C} /$ minute while being purged with dry nitrogen (Samy E.M., 2000).

\section{- Powder X-ray diffractometry (PXRD) studies}

Powder X-ray diffraction (PXRD) patterns were traced employing an X-ray diffractometer (Philips PW 1729 Netherlands.) for all the samples, using an Ni filter, $\mathrm{Cu} \mathrm{K}(\alpha)$ radiation, a voltage of $\mathrm{kV}$, a current of $20 \mathrm{~mA}$ and a receiving slit of 0.2 inches. The samples were analyzed over a $2 \theta$ range of $5^{\circ}$ to $60^{\circ}$, with a scan step size of $0.020^{\circ}$ (20) and scan step time of 1 second (Samy E.M., 2000).

\section{In vitro dissolution studies}

Release from the solid dispersions was determined in a calibrated 8-station USP XXII apparatus (paddle method), TDT-08L Electrolab, Mumbai, India. Samples of drug, solid dispersions and physical mixture equivalent with $10 \mathrm{mg}$ of drug were packed into thin cloth thimbles and then immersed in the dissolution medium consisting of $900 \mathrm{ml} 0.1 \mathrm{~N} \mathrm{HCl}$ maintained at $37^{\circ} \mathrm{C}$. The duration of the test and the rate of paddle stirring were $90 \mathrm{~min}$ and 75 rpm, respectively. At a time intervals of $(5,10,15,20,30$, 45, 60 and 90 minutes), $5 \mathrm{ml}$ samples were withdrawn, and replaced with $5 \mathrm{ml}$ of fresh dissolution medium. The samples were filtered through a whatman filter paper No. 1 and analyzed spectrophotometrically at $250 \mathrm{~nm}$ on a Varian carry 100, UV-vis Spectrophotometer, Australia. 
Cumulative percentages of the drug dissolved from the preparations were calculated (Pignatello et al., 2002; Mahaparale et al., 2006).

\section{Data analysis}

- $\quad$ Phase-solubility studies

The values of apparent stability constant, Ks, between each drug-carrier combination were computed from the phase-solubility profiles, as described below:

$$
\mathrm{Ks}=\text { Slope } / \text { Intercept }(1-\text { slope })
$$

The values of Gibbs free energy of transfer, $\Delta \mathrm{G}_{\mathrm{tr}}{ }_{\mathrm{tr}}$ of ALLO from aqueous solution of the carriers were calculated according to the following relationship

$$
\Delta \mathrm{G}_{\mathrm{tr}}^{\mathrm{o}}=-2.303 \mathrm{RT} \cdot \log \mathrm{So} / \mathrm{Ss}
$$

Where So and Ss are the molar solubilities of ALLO in $1 \% \mathrm{w} / \mathrm{v}$ aqueous solution of the carrier, respectively.

In vitro drug release data was fitted to four popular models of data treatment for the formulations as follows:

1)Zero order: $F=k X t$

2) First order: $\ln F=k X t$

3) Higuchi's model: $F=k \sqrt{ }$

4) Korsmeyer and Peppas model: $F=k t^{n}$

Where $\mathrm{F}$ is the fraction of drug release, $\mathrm{k}$ is the release constant, $\mathrm{t}$ is the time and $\mathrm{n}$ is the diffusional coefficient. The value of $\mathrm{n}$ is related to the geometrical shape of the delivery system and determines the release mechanism from various polymeric drug deliveries.

\section{RESULTS AND DISCUSSION}

\section{Phase solubility studies}

The current study showed that PVPK30 and PEG 6000 have a significant solubilizing effect on ALLO. Figure 1 shows the phase-solubility curve of ALLO in the presence of PVPK30 and PEG 6000. The solubility of ALLO in water at R.T. $\left(25^{\circ} \mathrm{C}\right)$ is $137 \mu \mathrm{g} / \mathrm{mL}$; therefore, ALLO can be considered a water-insoluble drug. From this curve, it can be seen that the apparent solubility of ALLO increased with greater carrier concentrations. Both carriers show an $A_{L}$ type of linear graph with increasing concentration of carriers.

The obtained values of Gibbs free energy transfer $\left(\Delta \mathrm{G}_{\mathrm{tr}}^{\mathrm{o}}\right)$ (Table I) for apparent stability constants $(\mathrm{Ks})$ were
43.46 and 130.38 , for slope $3.78 \times 10^{-4}$ and $1.16 \times 10^{-3}$ with $\mathrm{R}^{2}$ values 0.9874 and 0.9823 , for PEG 6000 and PVPk30, respectively. Negative $\Delta \mathrm{G}_{\mathrm{tr}}{ }_{\mathrm{tr}}$ values indicate favorable conditions. These values also indicated that the extent of improvement in solubility was greater with PVP K30 compared with PEG 6000. The solubility enhancement of ALLO obtained with various carriers in water followed the rank order of PVP K30> PEG 6000.

TABLE I - Phase solubility parameters of Allopurinol at $25^{\circ} \mathrm{C}$

\begin{tabular}{lccc}
\hline \multirow{2}{*}{$\begin{array}{c}\text { Sr. } \\
\text { No. }\end{array}$} & $\begin{array}{c}\text { Polymer concentration } \\
(\% \mathrm{w} / \mathrm{v})\end{array}$ & \multicolumn{2}{c}{$\begin{array}{c}\text { Gibb's free energy of transfer } \\
\Delta \mathrm{G}_{\mathrm{tr}}^{0} \text { (joules/mol) }\end{array}$} \\
& 1 & PEG 6000 & PVP K30 \\
\hline 1 & 5 & -2.7 & -4.2 \\
2 & 10 & -5.2 & -7.0 \\
3 & & -7.6 & -8.5 \\
\hline
\end{tabular}

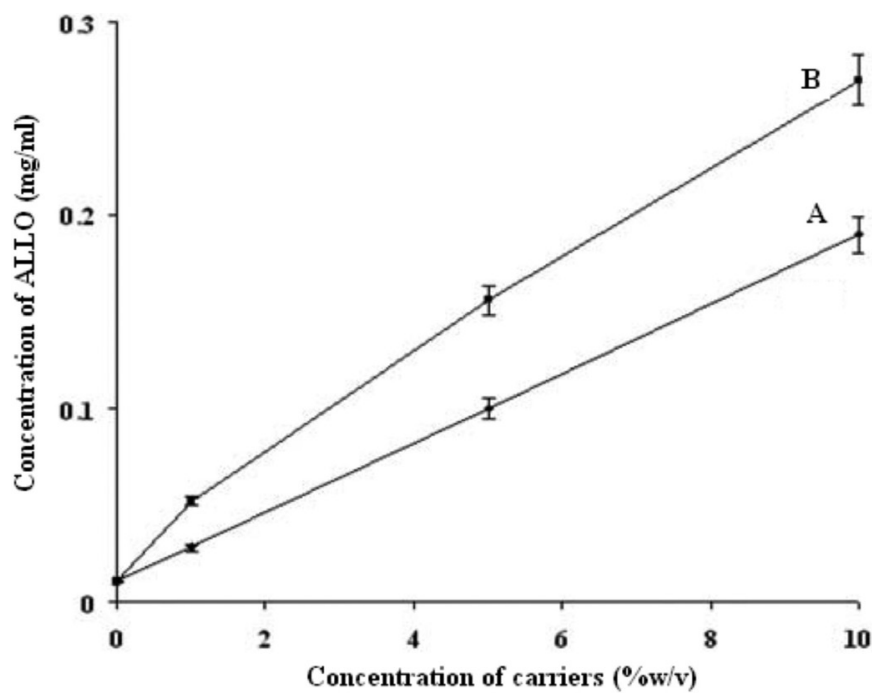

FIGURE 1 - Solubility of Allopurinol $(\mathrm{g} / 100 \mathrm{ml})$ in aqueous solutions of (A) PEG 6000 and (B) PVP K30 in water at $25^{\circ} \mathrm{C}$

\section{Characterization of solid dispersion}

\section{UV-Visible Spectroscopy studies}

UV absorption spectra of ALLO and its solid dispersions were determined in $0.1 \mathrm{M} \mathrm{NaOH}$ by scanning the sample solutions in the range $240 \mathrm{~nm}$ to $300 \mathrm{~nm}$ at a $1 \mathrm{~cm}$ path length. ALLO showed maximum absorption ( $\lambda \max )$ at $260 \mathrm{~nm}$. Figure 2 shows UV Spectra of allopurinol solid dispersions with PVP K30. The solutions of physical mixture and solid dispersions showed absorbance at the same $\lambda \max$ i.e. $260 \mathrm{~nm}$ but all formulations showed slight difference in absorbance compared to allopurinol. The decrease in absorbance showed by all solid disper- 
sions (except KN2-K30 and CG4-K30 that exhibited increased absorbance) was due to method variation and considered practical errors such as formation of sticky lumps. This indicates there is no significant evidence of chemical interaction between ALLO and PVP K30. The shift in wavelength might be due to the complete incorporation of drug into the carrier.

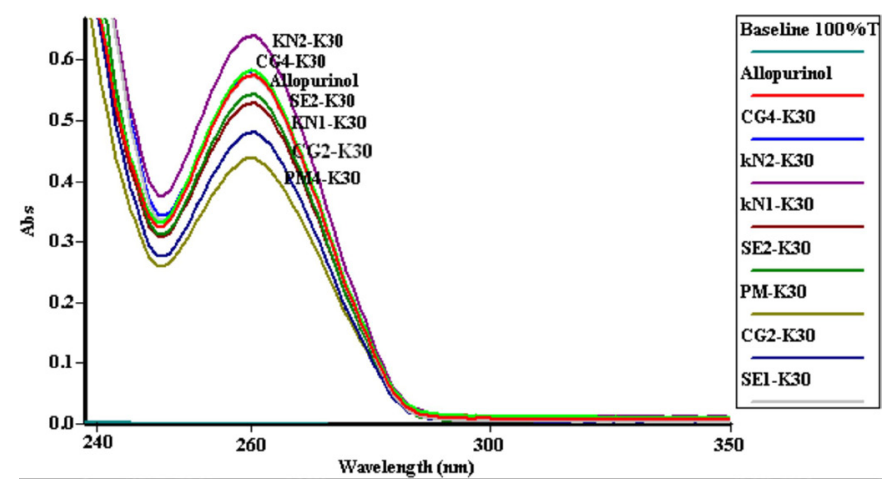

FIGURE 2 - UV Spectra of Allopurinol SDs with PVP k30

Figure 3 shows the UV spectra of ALLO and its solid dispersions with PEG 6000. The UV absorption spectra of ALLO and its solid dispersions in PEG 6000 were obtained at the same scanning rate as PVPk30. All the dispersions exhibited decreased absorbance but the spectra of all solid dispersions were shifted to the higher wavelength due to the high polarity of the solvent i.e. $\mathrm{NaOH}$ as shown in Figure 3. This is considered significant evidence of chemical interaction between ALLO and PEG 6000.

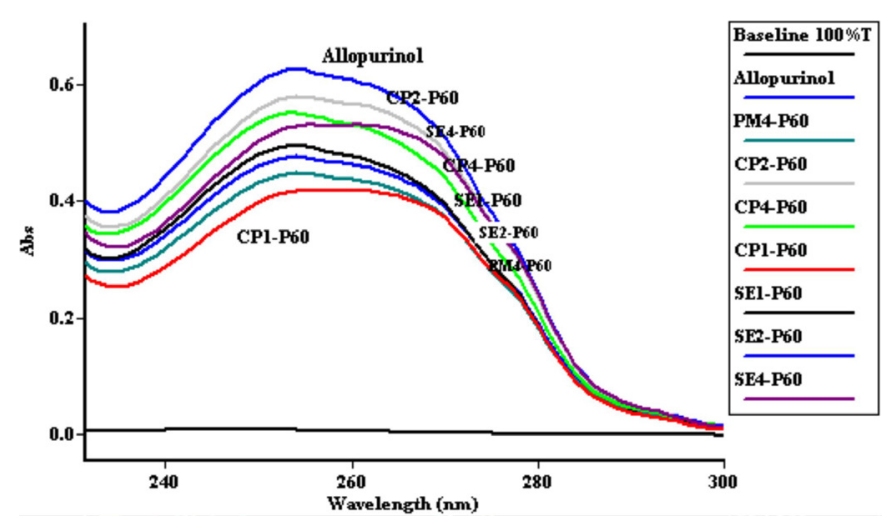

FIGURE 3 - UV Spectra of Allopurinol SDs with PEG 6000

Fourier Transform Infrared spectroscopy (FTIR) studies

The FTIR spectrum of ALLO exhibited characteristic signals at $790,811,915,1159$, and $1232 \mathrm{~cm}^{-1}(\mathrm{CH}$ in plane deformation), $1590 \mathrm{~cm}^{-1}$ (ring vibration), 1700 and $1763 \mathrm{~cm}^{-1}$ (CO stretching vibration of the keto form of the 4-hydroxytautomer), $3060 \mathrm{~cm}^{-1}$ (CH stretching vibrations of pyrimidine ring), $3400 \mathrm{~cm}^{-1}$ (NH stretching band), respectively.

Important vibrations detected in the spectrum of PEG 6000 are $\mathrm{C}-\mathrm{H}$ stretching at $2890 \mathrm{~cm}^{-1}$ and $\mathrm{C}-\mathrm{O}$ (ether) stretching at $1125 \mathrm{~cm}^{-1}$.

The spectra of the physical mixture (PM2-P60) can simply be regarded as the superimposition of those of ALLO and PEG 6000 (Figure 4). No difference was observed in the position of the absorption bands of ALLO and PEG 6000. The characteristic peaks of PEG 6000 were present at almost the same positions, while the absence of shifts in the wave numbers of the FTIR peaks of the solid dispersions vis-a-vis the PM indicate the lack of significant interaction between the drug and the carrier in the solid dispersions. Thus, these results confirm the absence of any well-defined interaction between ALLO and PEG 6000.

Figure 5 displays the FTIR spectra of pure ALLO, PVP K30, PM and solid dispersions prepared by KN, $\mathrm{CG}$ and SE methods. PVP K30 exhibited peaks of C-H stretch vibration $\left(2955 \mathrm{~cm}^{-1}\right)$ and $-\mathrm{C}=\mathrm{O}$ stretch vibration $\left(1663 \mathrm{~cm}^{-1}\right)$. The solid dispersions of all ratios $(1: 1,1: 2$ and 1:4) showed that the principle peaks of ALLO i.e. 1700 and $1763 \mathrm{~cm}^{-1}$ (CO stretching vibration of the keto form of the 4-hydroxytautomer), $3060 \mathrm{~cm}^{-1}$ (CH stretching vibrations of pyrimidine ring), $3400 \mathrm{~cm}^{-1}$ (NH stretching band) were smoothened, weakened and splits. These observations indicated intermolecular hydrogen bonding via $\mathrm{N}-\mathrm{H}$, $\mathrm{C}-\mathrm{H}$ and $\mathrm{C}-\mathrm{O}$ groups of $\mathrm{ALLO}$ and $-\mathrm{C}=\mathrm{O}$ stretch vibration of PVP. This result confirms significant drug-polymer interaction (Shah et al., 2007; Gurusamy et al., 2006).

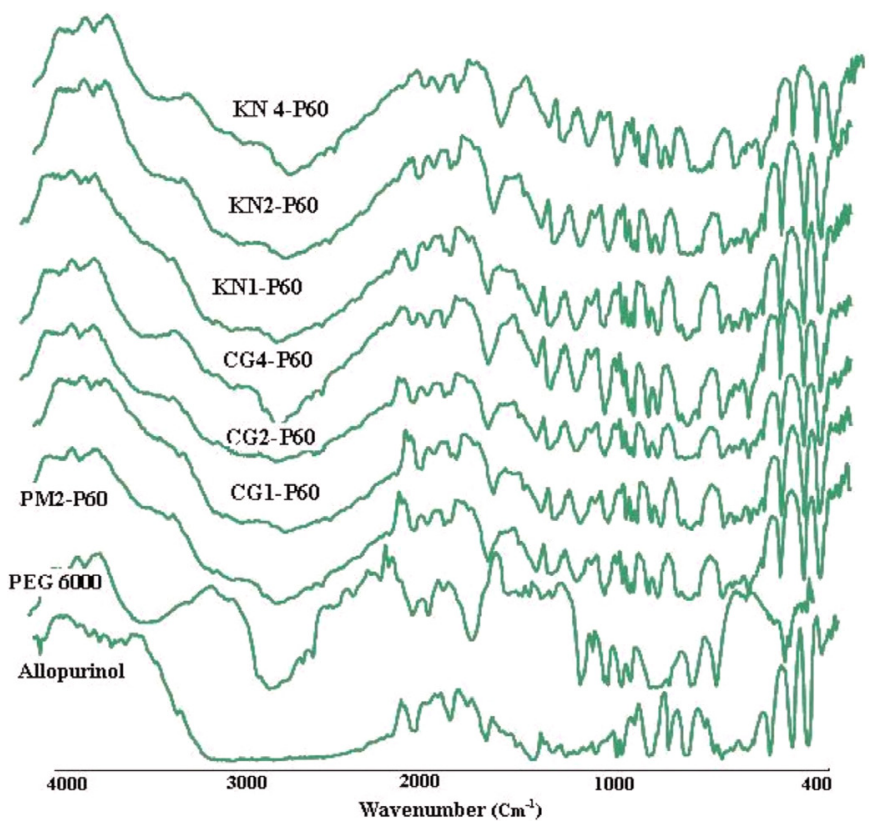

FIGURE 4 - FT-IR spectra of Allopurinol, physical mixture and its solid dispersions in PEG 6000 by CG and KN methods. 


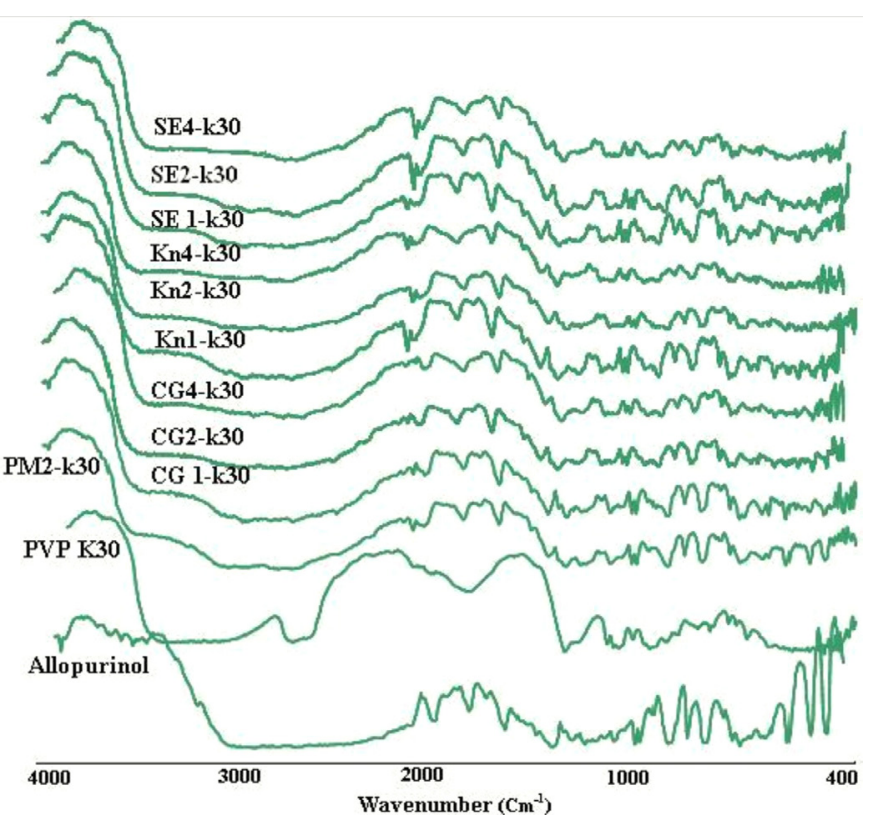

FIGURE 5 - FT-IR spectra of Allopurinol, physical mixture and its solid dispersions in PVP K30 CG, by KN and SE methods.

\section{Differential Scanning Calorimetry (DSC) studies}

The DSC curve of ALLO and PEG 6000 showed sharp endothermic peaks at $379.5^{\circ} \mathrm{C}$ and $62.7^{\circ} \mathrm{C}$ respectively, due to fusion (Figure 6) corresponding to its melting point. The DSC curve of (CM4-P60) solid dispersion prepared by $\mathrm{CM}$ showed that the sharp endothermic peak was equivalent to the addition curves of PEG 6000 and crystalline drug (ALLO). It indicates lower crystallinity because of less cross-linking between ALLO and PEG 6000 . The physical mixture and solid dispersion prepared by the solvent evaporation method (SE2-P60) showed an ALLO and PEG 6000 derived endothermic peak with lower intensity than pure ALLO. The possibility of drug dissolution in the melting carrier has been previously reported (Okonogi et al., 2006) Therefore, DSC results suggested that crystalline ALLO in the ALLO-PEG solid dispersions were dissolved in melting PEG during the DSC scan.

Figure 7 shows the DSC curves of ALLO, PVPk30 and solid dispersions (KN4-K30, SE1-K30 and CG2$\mathrm{K} 30)$. ALLO and PVPk30 show endothermic peaks at $379.5^{\circ} \mathrm{C}$ and $80^{\circ} \mathrm{C}$, respectively. The sharp endothermic peaks corresponding to melting of ALLO becomes broad in DSC thermograms of solid dispersions. However, solid dispersion (KN4-K30) showed the ALLO-derived endothermic peaks with greater intensity than pure ALLO. This might be due to the amorphous form of ALLO in the solid dispersion or dissolution of crystalline ALLO into the molten carrier.
The shift and breadth of the endothermic peaks probably results from the partial reduction in crystallinity of ALLO, which can be confirmed in PXRD studies.

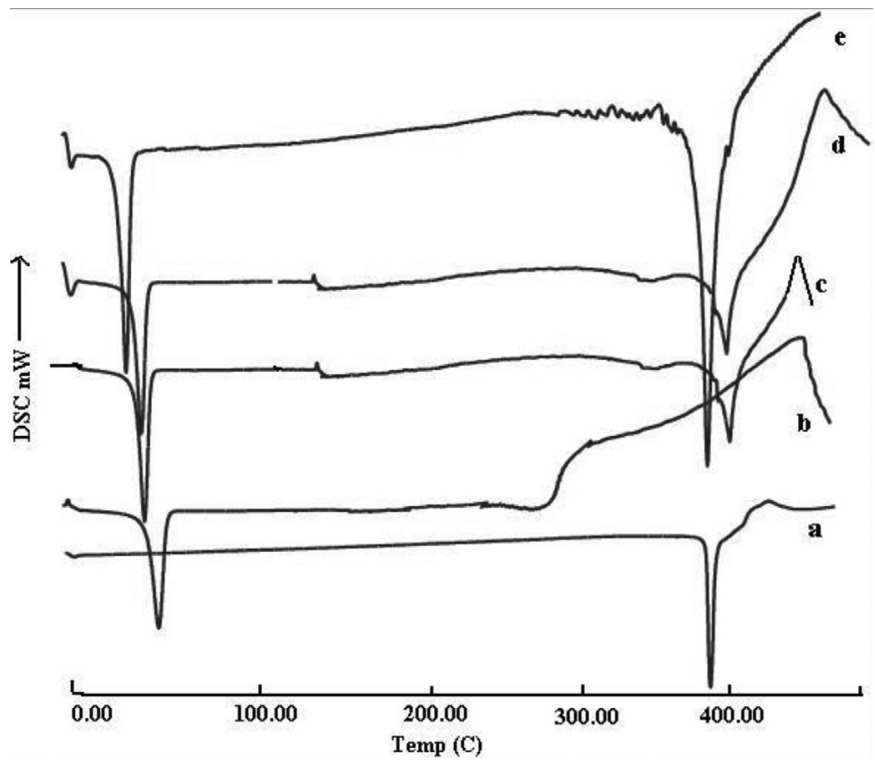

FIGURE 6 - DSC Thermographs of SDs with PEG 6000; a) ALLO, b) PEG 6000, c) PM-P60, d) SE2-P60, e) CM4-P60.

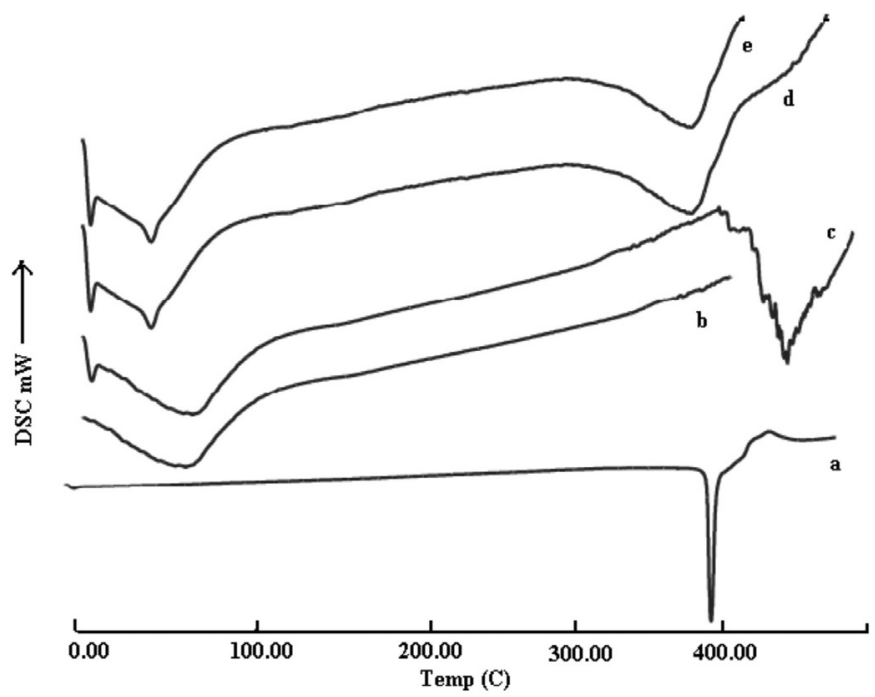

FIGURE 7 - DSC Thermographs of SDs with PVP K30; a) ALLO, b) PVP K30, c) KN4-K30, d) SE1-K30, e) CG2-K30.

Powder X-ray diffractometry (PXRD) studies

The diffraction peaks of ALLO, carriers, PM and solid dispersions were given for comparative purposes. The PXRD patterns of ALLO, PEG 6000 and its binary systems are compared in Figure 8. The diffraction pattern of pure drug reveals its highly crystalline nature, as indicated by the numerous distinctive peaks. The PEG 6000 alone exhibited two high intensity peaks at $19^{\circ}$ and 
$23^{\circ}$. The lack of the numerous distinctive peaks of the drug in the PM and solid dispersions demonstrated that a high concentration of the drug was dissolved in solid state carrier matrix in an amorphous state. This suggests the ALLO present in the solid dispersion is mostly in an amorphous state with only few partially crystallized drug molecules.

PXRD patterns of ALLO, PVP K30, PM and solid dispersions are shown in Figure 9. In the X-ray diffractograms of ALLO, sharp peaks at a diffraction angle (20) of $7.01^{\circ}, 9.66^{\circ}, 11.5^{\circ}, 19.21^{\circ}, 20.08^{\circ}$ and $35.07^{\circ}$ indicate the presence of crystalline drug, while PM and solid dispersion show a single sharp peak at $24.88^{\circ}$. These data revealed that the diffraction patterns of all the samples of solid dispersions have peaks due to PVP but the typical drug crystalline peaks are totally absent, thus indicating the crystalline nature of ALLO converted to an amorphous state (Shah et al., 2007; Gurusamy et al., 2006).

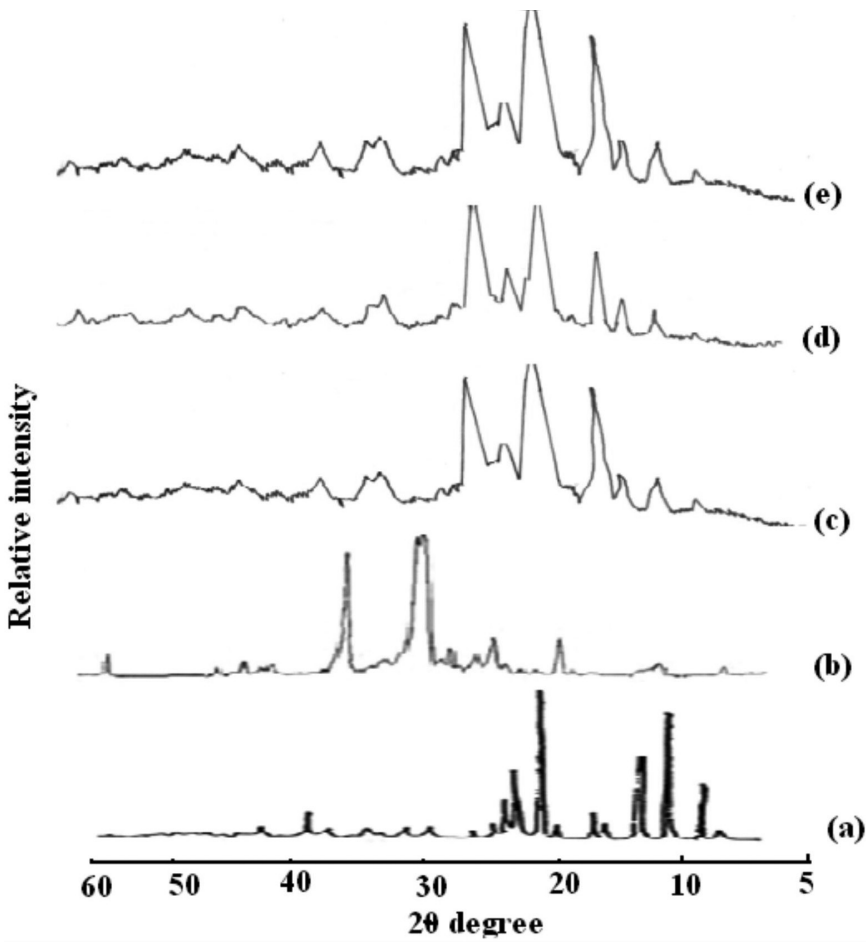

FIGURE 8 - PXRD pattern of SDs with PEG 6000; a) ALLO, b) PEG 6000, c) PM4-P60, d) CM4-P60, e) CG2-P60.

\section{In vitro dissolution study}

The dissolution rate of pure ALLO was very poor and during a 90 -minute period, a maximum of around $54.53 \%$ of drug was released. The reason for the poor dissolution of pure drug could be poor wettability and/or agglomeration.

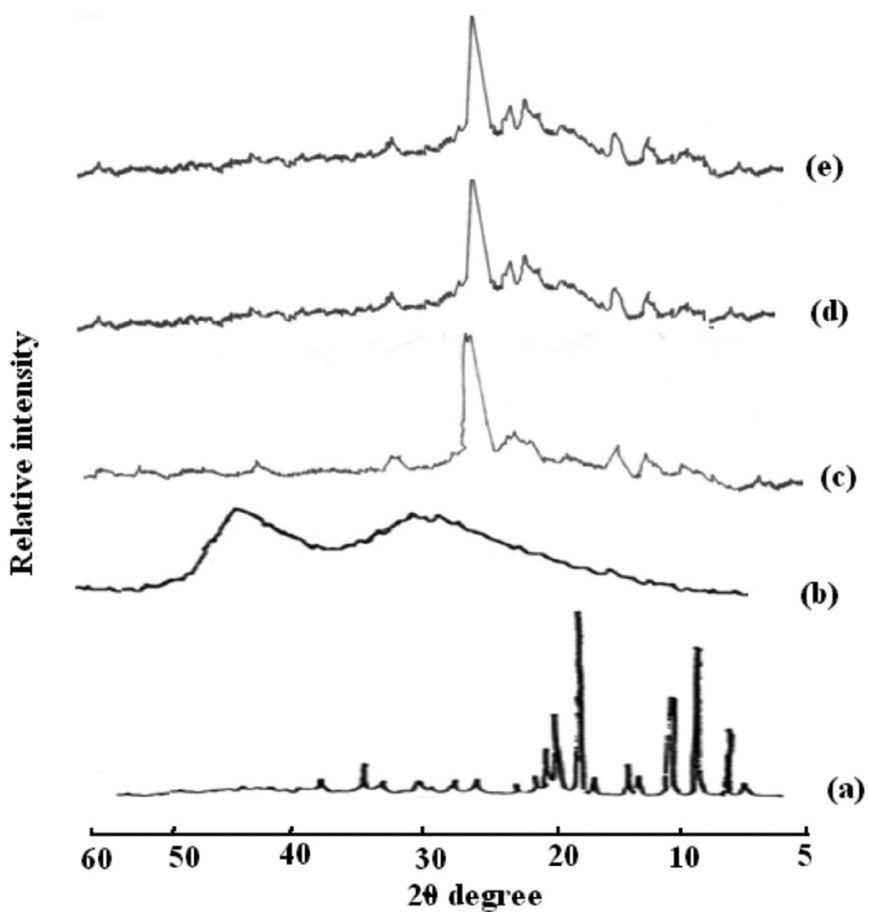

FIGURE 9 - PXRD pattern of SDs with PVP K30; a) ALLO, b) PVP K30, c) PM-K30, d) SE1-K30, e) KN4-K30.

Figure 10, Figure 11 and Figure 12 show the plot of cumulative per cent drug released as a function of time for different formulations. In vitro release studies revealed that there was a marked increase in the dissolution rate of ALLO, in the range of 65.8 to $99.8 \%$, from all Physical mixtures and solid dispersions compared to pure ALLO except for CP2-P60, KN1-P60 and CM1-P60 (Figure 10, Figure 11 and Figure 12). This might be secondary to the improper distribution of drug in these formulations due to the method variation. Among the different ratios prepared, the enhancement of dissolution rate was found to be $1: 4>1: 2>1: 1$.

The results revealed that the solid dispersions produced by co-grinding and solvent evaporation techniques have higher dissolution rates of pure ALLO at all ratios compared with the samples produced by $\mathrm{KN}, \mathrm{CP}$ and $\mathrm{CM}$ methods. This could be due to molecular dispersion of drug in the samples and drug amorphization. Hence, the present study showed the SE and CG techniques are more efficient than $\mathrm{KN}, \mathrm{CP}$ and $\mathrm{CM}$ techniques for increasing the dissolution of ALLO by using PEG 6000 as a hydrophilic carrier.

Figures 13 and 14 show comparative in vitro release profiles of pure ALLO, physical mixture and various solid dispersions of ALLO with PVP K30, prepared by the KN, $\mathrm{CG}$ and SE methods. In vitro release studies revealed a marked increase in dissolution rate of ALLO from all 


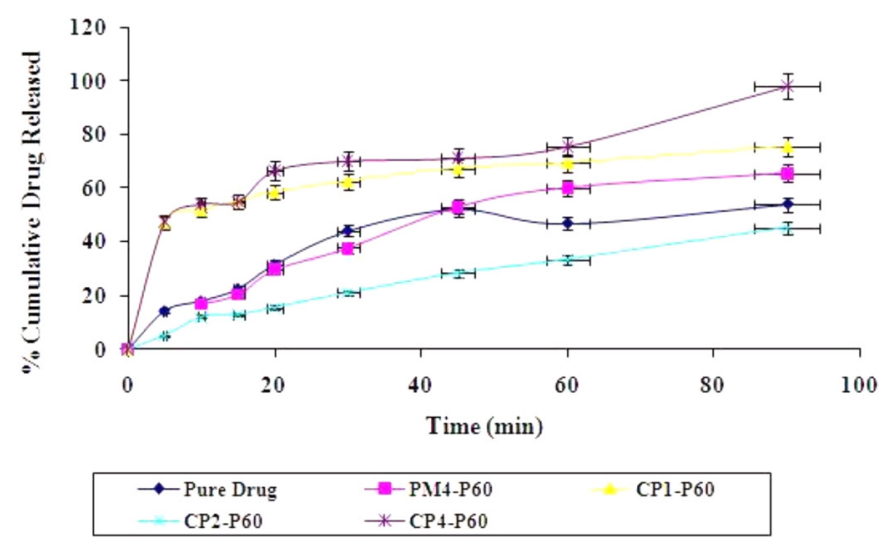

FIGURE 10 - In vitro Drug release profile of ALLO-PEG 6000 binary systems by Co-precipitation method.

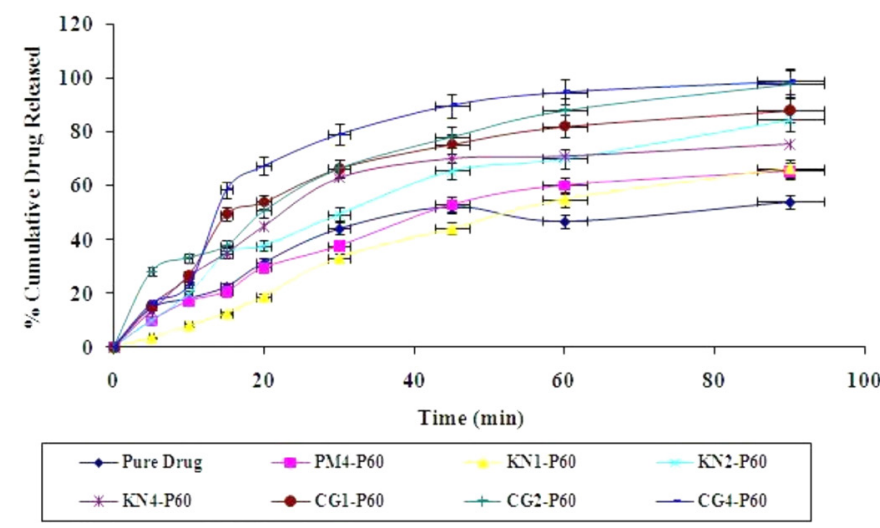

FIGURE 11 - In vitro Drug release profile of ALLO-PEG 6000 binary systems by kneading and Co-grinding methods.

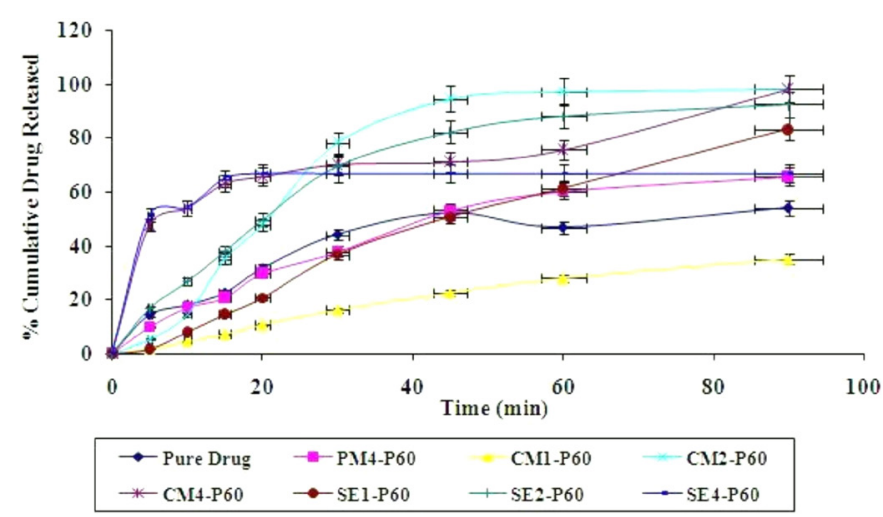

FIGURE 12 - In vitro Drug release profile of ALLO-PEG 6000 binary systems by Closed melting and Solvent evaporation methods.

solid dispersions when compared to pure ALLO. Based on the release profile, 1:2 ratios of $\mathrm{KN}$ and $\mathrm{CG}$ methods showed consistency in the release pattern of drug after 20 minutes without increasing the further release of drug. This stoppage in the dissolution rate may be due to the increase in the viscosity of coating material. The increase in dissolution rate may be the result of solubility enhancement by improving the wettability of drug particles due to its surfactant property.

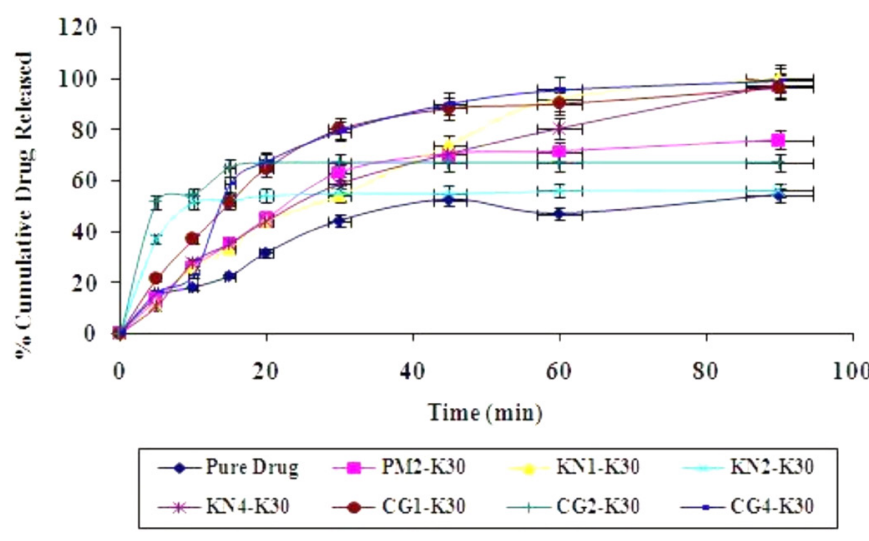

FIGURE 13 - In vitro Dissolution profile of ALLO-PVP K30 binary systems by kneading and Co-grinding methods.

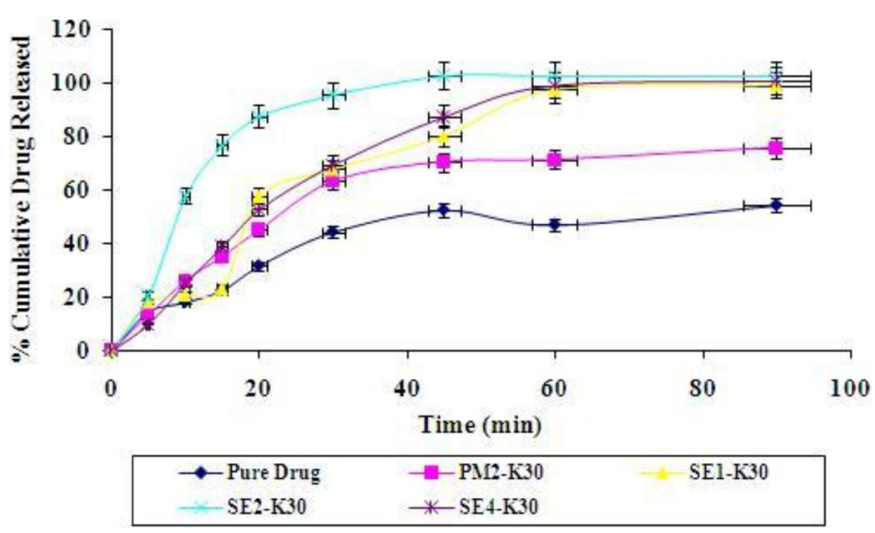

FIGURE 14 - In vitro Drug release profile of ALLO-PEG 6000 binary systems by Closed melting and Solvent evaporation methods.

\section{Kinetic treatment of dissolution data}

The coefficient of determination was considered the main parameter for interpreting the results. The $\mathrm{n}$ values of all formulations are as reported in Table II and III. All formulations of solid dispersions were not fitting to a specific model (Patel et al., 2008).

Only two formulations, i.e. KN4-P60 and CG1-P60, followed first order kinetics with $\mathrm{R}^{2}$ values of 0.9708 and 0.9838, respectively. Formulations KN1-P60, CM1-P60, CP1-P60, CP2-P60, and SE1-P60 follow Higuchi kinetics with $R^{2}$ values $0.9874,0.9954,0.9848,0.9897$ and 0.9938 , respectively.

The release kinetic analyses of all formulations are as shown in Table 2. For formulations containing PEG 6000, KN1-P60, CM1-P60, CM2-P60 and SE1-P60, n values were $1.0495,1.036,1.0372$ and 1.2869 , respec- 
TABLE II - Kinetic treatment of dissolution data of allopurinol Solid Dispersions in PEG 6000

\begin{tabular}{|c|c|c|c|c|c|}
\hline \multirow{2}{*}{$\begin{array}{l}\text { Formulation } \\
\text { Code }\end{array}$} & \multicolumn{5}{|c|}{ Coefficient of determination( $(\mathrm{r} 2)$} \\
\hline & Zero order & First order & $\begin{array}{l}\text { Higuchi } \\
\text { square }\end{array}$ & $\begin{array}{l}\text { Korsemeyer } \\
\text { Peppas }\end{array}$ & $\begin{array}{c}\text { Korsemeyer } \mathrm{n} \\
\text { (release exponent) }\end{array}$ \\
\hline ALLO & 0.9251 & 0.9197 & 0.8711 & 0.9262 & 0.5134 \\
\hline PM4-P60 & 0.9809 & 0.9557 & 0.9726 & 0.9821 & 0.69 \\
\hline KN1-P60 & 0.9699 & 0.9222 & 0.9874 & 0.9815 & 1.0495 \\
\hline KN2-P60 & 0.9879 & 0.9184 & 0.978 & 0.9527 & 0.7282 \\
\hline KN4-P60 & 0.9533 & 0.9708 & 0.8855 & 0.9209 & 0.6052 \\
\hline CM1-P60 & 0.9721 & 0.9527 & 0.9954 & 0.9804 & 1.036 \\
\hline CM2-P60 & 0.9455 & 0.9249 & 0.878 & 0.8901 & 1.0372 \\
\hline CM4-P60 & 0.8822 & 0.5627 & 0.9201 & 0.9285 & 0.2174 \\
\hline CP1-P60 & 0.9937 & 0.9731 & 0.9848 & 0.9967 & 0.1648 \\
\hline CP2-P60 & 0.9422 & 0.9051 & 0.9897 & 0.9785 & 0.7042 \\
\hline CP4-P60 & 0.8929 & 0.5736 & 0.9278 & 0.9219 & 0.2272 \\
\hline SE1-P60 & 0.9609 & 0.8303 & 0.9938 & 0.9531 & 1.2869 \\
\hline SE2-P60 & 0.9771 & 0.9566 & 0.9279 & 0.9552 & 0.6311 \\
\hline SE4-P60 & 0.6414 & 0.6498 & 0.521 & 0.6878 & 0.093 \\
\hline CG1-P60 & 0.9639 & 0.9838 & 0.9021 & 0.9037 & 0.5974 \\
\hline CG2-P60 & 0.9811 & 0.7955 & 0.9717 & 0.9684 & 0.4817 \\
\hline CG4-P60 & 0.9212 & 0.9141 & 0.8369 & 0.8497 & 0.6573 \\
\hline
\end{tabular}

Kinetic treatment for PEG 6000 solid dispersions

tively, indicating that the release mechanism from these systems was super case II transport. Formulations KN2P60, KN4-G50, CP2-P60, SE2-P60, CG1-P60, CG2-P60 and CG4-P60, had $\mathrm{n}$ values ranging from 0.4817 to 0.7282 indicating that the release mechanism from these systems was the anomalous type (Non Fickian transport), which refers to a combination of both diffusion and erosion controlled-drug release.

\section{Kinetic treatment for PVP K30 solid dispersions}

Only one formulation i.e. SE2-K30, followed first order kinetics with an $\mathrm{R}^{2}$ value of 0.9827 . Formulations KN1-K30 and KN4-30 followed Higuchi kinetics with $\mathrm{R}^{2}$ values of 0.983 and 0.988 , respectively. The release kinetic analyses of all formulations are as shown in Table 3. All formulations showed $\mathrm{n}$ values ranging from 0.5207 to 0.7361 except KN2-K30 and CG2-K30, whose n values were less than 0.5 and hence their release mechanism is not understood. Given these $\mathrm{n}$ values, it is concluded that the release mechanism from these systems was the anomalous type (Non Fickian transport), which refers to a combination of both diffusion and erosion controlleddrug release.

\section{CONCLUSION}

Finally, based on the above study, it was concluded that the solid dispersion technique was shown to be a successful approach for improving the dissolution rate of allopurinol. The nature and amount of the carrier used played an important role in the enhancement of the dissolution rate. The increased solubility and dissolution rate of ALLO provided the rapid onset of action.

\section{ACKNOWLEDGEMENTS}

The authors are grateful to the Maharashtra Institute of pharmacy, Pune for providing essential laboratory conditions for the research work. Also, an author acknowledges the Department of Physics, University of Pune, for allowing the X-ray Diffraction and Differential Scanning Calorimetric studies. 
TABLE III - Kinetic treatment of dissolution data of allopurinol Solid Dispersions in PVP K30

\begin{tabular}{lccccc}
\hline $\begin{array}{l}\text { Formulation } \\
\text { Code }\end{array}$ & Zero order & First order & $\begin{array}{c}\text { Coefficient of determination(r2) } \\
\text { Square }\end{array}$ & $\begin{array}{c}\text { Korsemeyer } \\
\text { Peppas }\end{array}$ & $\begin{array}{c}\text { Korsemeyer } \mathrm{n} \\
\text { (release exponent) }\end{array}$ \\
\hline ALLO & 0.9251 & 0.9197 & 0.8711 & 0.9262 & 0.5134 \\
PM2-K30 & 0.9532 & 0.9611 & 0.8778 & 0.9147 & 0.5207 \\
KN1-K30 & 0.9839 & 0.6239 & 0.983 & 0.9736 & 0.7361 \\
KN2-K30 & 0.574 & 0.6111 & 0.4881 & 0.6336 & 0.1144 \\
KN4-K30 & 0.9925 & 0.7554 & 0.988 & 0.9486 & 0.7158 \\
CG1-K30 & 0.9532 & 0.9685 & 0.8793 & 0.9161 & 0.5227 \\
CG2-K30 & 0.6414 & 0.6498 & 0.521 & 0.6878 & 0.093 \\
CG4-K30 & 0.9217 & 0.9172 & 0.8373 & 0.8501 & 0.6579 \\
SE1-K30 & 0.9499 & 0.8294 & 0.906 & 0.8879 & 0.7044 \\
SE2-K30 & 0.7576 & 0.9827 & 0.6478 & 0.7078 & 0.4681 \\
SE4-K30 & 0.9826 & 0.7535 & 0.9329 & 0.9248 & 0.8008 \\
\hline
\end{tabular}

\section{REFERENCES}

ABDUL-FATTAH, A.M.; BHARGAVA, H.N. Preparation and in vitro evaluation of solid dispersions of halofantrine. Int. J. Pharm., v.235, p.17-33, 2002.

AHUJA, N.; KATARE, O.; SINGH, B. Studies on dissolution enhancement and mathematical modeling of drug release of a poorly water-soluble drug using water-soluble carriers. Eur. J. Pharm. Biopharm., v.65, p.26-38, 2007.

AHUJA, N.; SINGH, A.; SINGH, B. Rofecoxib: an update on physicochemical, pharmaceutical, pharmacodynamic and pharmacokinetic aspects. J. Pharm. Pharmacol., v.55, p.859-894, 2003.

CHOW, A.H.L. Assessment of wettability and its relationship to the intrinsic dissolution rate of doped phenytoin crystals. Int. J. Pharm.,v.126, p.21-28,1995.

CRAIG, D.Q.M. The mechanisms of drug release from solid dispersions in water-soluble polymers. Int. J. Pharm., v.231, p.131-144, 2002.

DAMIAN, F.; BLATON, N.; KINGET, R.; NAESENS L.; BALZARINI, J.; AUGUSTIJNS, P.; VAN DEN MOOTER, G. Physicochemical characterization of solid dispersions of the antiviral agent UC-781 with polyethylene glycol 6000 and Gelucire 44/14. Eur. J. Pharm Sci., v.10, p.311-322, 2000 .
DIXIT, R.P.; NAGARSENKAR, M.S. In vitro and in vivo advantage of Celecoxib surface solid dispersion and dosage form development. Ind. J. Pharm. Sci., v.69, p.370-377, 2007.

FLEGO, C. Dissolution rate of griseofulvin from solid dispersion with poly(vinylmethylether: maleic anhydride). Drug Dev. Ind. Pharm., v.14, p.1185-1202, 1988.

GEORGE, Z.; BIKIARIS, D.; KARAVAS, E. Effect of physical state and particle size distribution on dissolution enhancement of nimodipine/PEG solid dispersions prepared by melt mixing and solvent evaporation. AAPS PharmSciTech., v.8, p.E623-E631, 2006.

GURUSAMY, S.; VIJAY, K.; MISHRA D. Preparation, characterization and in vitro dissolution studies of solid dispersions meloxicam with PEG 6000. Yakugaku Zasshi., v.126, p.657-664, 2006.

HABIB, F.S.; ATTIA, M. A. Effect of particle size on the dissolution rate of monophenylbutazone solid dispersion in presence of certain additives. Drug Dev. Ind. Pharm., v.11, p.2009-2019, 1985

HASEGAWA, S.; HAMAURA, T.; FURUYAMA, N. Effects of water content in physical mixture and heating temperature on crystallinity of tropiglitazone- PVP K30 solid dispersions prepared by closed melting method. Int. J. Pharm., v.302, p.103-112, 2005. 
HIGUCHI, T.; CONNORS, K.A. Phase solubility techniques. Adv. Anal. Chem. Instr., v.4, p.117-212, 1965.

LONDHE, V.Y.; NAGARSENKAR, M.S. Solid dispersion of hydroxypropyl $\beta$ - cyclodextrin and carbamazepine: study of complexation and in vitro dissolution profile. Indian drugs, v.36, p.15-20, 1999.

MAHAPARALE, P.R.; GUDSOORKAR, V.R.; GAJELI, G.B. Studies on solid dispersions of meloxicam. Ind. J. Pharm. Educ. Res., v.40, p.241-244, 2006.

MODI, A.; TAYADE, P. Enhancement of dissolution profile by solid dispersion (kneading) technique. AAPS PharmSciTech., v.7, p.E1-E6, 2006.

NOKHODCHI, A.; TALARI, R.; VALIZADEH, H. An investigation on the solid dispersions of chlordiazepoxide. Int. J. Biomedical. Sci.,v.3, p.211-217, 2007.

OKONOGI, S.; PUTTIPIPATKHACHORN, S. Dissolution improvement of high drug-loaded solid dispersion. AAPS PharmSciTech.,v.7, p.52, E1-E6, 2006.

PATEL, N.; CHOTAI, N.; PATEL, J. Comparison of in vitro dissolution profiles of oxcarbazepine-HP b-CD tablet formulations with marketed oxcarbazepine tablets. Dissol. Technol., v.15, p.28-34, 2008.

PATHAK, D.; DAHIYA, S.; PATHAK, K. Solid dispersion of meloxicam: factorially designed dosage form for geriatric population. Acta Pharm., v.58, p.99-110, 2008.
PIGNATELlO, R.; FERRO, M.; PUGLISI, G. Preparation of solid dispersions of non-steroidal anti-inflammatory drugs with acrylic polymers and studies on mechanisms of drug-polymer interactions. AAPS PharmSciTech., v.3, p.1-11, 2002.

PITHA, J. Amorphous water-soluble derivatives of cyclodextrins: nontoxic dissolution enhancing excipients. J. Pharm. Sci., v.74, p.987-990, 1985.

SAMY, E.M. Improvement of availability of allopurinol from pharmaceutical dosage forms I - suppositories. Eur. J. Pharm. Biopharm., v.49, p.119-127, 2000.

SEKIGUCHI, K. Dissolution behavior of solid drugs. III. Determination of the transition temperature between the hydrate and anhydrous forms of phenobarbital by measuring their dissolution rates. Chem. Pharm. Bull., v.21, p.1592$1600,1973$.

SERAJUDDIN, A. T. M. Solid dispersion of poor water-soluble drugs: early promises, subsequent problems, and recent breakthroughs. J. Pharm. Sci., v.88, p.1058-1066, 1999.

SETHIA, S.; SQUILLANTE, E. Solid dispersion of carbamazepine in PVP K30 by conventional solvent evaporation and supercritical methods. Int. J. Pharm., v.272, p.1-10, 2004

SHAH, T.J.; AMIN A.F.; PARIKH J.R. Process optimization and characterization of poloxamer solid dispersions of a poorly water-soluble drug. AAPS PhaemScitTech., v.8, p.E1-E7, 2007.

Received for publication on $6^{\text {th }}$ December 2010 Accepted for publication on $12^{\text {th }}$ May 2011 
